\title{
Stigma experienced by family members of people with intellectual and developmental disabilities: multidimensional construct
}

\author{
Natasha Mitter, Afia Ali and Katrina Scior
}

\section{Background}

There is a lack of good-quality instruments measuring stigma experienced by family members of stigmatised people.

\section{Aims \\ To develop a self-report measure of stigma among families of people with intellectual and developmental disabilities and examine associations between family stigma and other variables.}

\section{Method}

The new Family Stigma Instrument (FAMSI) was tested with 407 family carers, $53 \%$ of whose offspring had an autism spectrum disorder in addition to intellectual disability. They also completed measures of subjective well-being, caregiver burden, selfesteem and social support.

\section{Results}

The FAMSI yielded a five-factor structure and had good reliability Perceived family stigma, caregiver burden and subjective wellbeing were the strongest predictors of family stigma.

\section{Conclusions}

This instrument can advance our understanding of the impact of stigma on family members. It can also help us understand sociodemographic, psychosocial and contextual variables of both the carer and cared for person that may influence family members' experiences.

\section{Declaration of interest}

None.

\section{Keywords}

Stigma; attitudes; family; intellectual disability; developmental disability; autism

\section{Copyright and usage}

(c) The Royal College of Psychiatrists 2018. This is an Open Access article, distributed under the terms of the Creative Commons Attribution-NonCommercial-NoDerivatives licence (http://creativecommons.org/licenses/by-nc-nd/4.0/), which permits noncommercial re-use, distribution, and reproduction in any medium, provided the original work is unaltered and is properly cited. The written permission of Cambridge University Press must be obtained for commercial re-use or in order to create a derivative work.
Individuals with intellectual and developmental disabilities (IDD, intellectual disabilities are also known as learning disabilities in UK health services) face stigma, prejudice and significant obstacles that restrict their human rights. ${ }^{1}$ Stigma has been conceptualised as a mark of social disgrace in which the targeted individual is discredited based on attributes such as ethnicity, mental health problems, disability or drug use. ${ }^{2}$ Four forms of stigma have been delineated in the literature. The first, public stigma, refers to the attitudes held by society about the stigmatised individual. ${ }^{3}$ The second, institutional stigma, occurs when policies reduce the choice of the stigmatised person. ${ }^{4}$ Self-stigma, the third form, occurs when the stigmatised person becomes aware of, endorses and internalises public stigma. ${ }^{3}$ Typically, studies have focused on self-stigma as experienced by the stigmatised person. Often, however, people associated with the target individual are also subjected to stigmatisation. This fourth type of stigma has been referred to as family stigma, courtesy stigma $^{2}$ or associative stigma. ${ }^{5}$ Relatedly, the construct of affiliate stigma involves the internalisation of stigma by associates of targeted individuals, such as caregivers. This differentiates it from courtesy or associative stigma, which focus mainly on others' perceptions of associates, but not on how the latter themselves respond to being viewed negatively.

The aforementioned terms describing experiences of stigma by caregivers have been used largely interchangeably in the literature. In general, there is a lack of clarity surrounding the effects of stigma on the family. Research on the effects of stigma on families has focused on Chinese cultures ${ }^{6-9}$ and Israel. ${ }^{10,11}$ Similar to theorising on attitudes, ${ }^{12}$ family stigma has been conceptualised as having three components: affect, cognitions and behavioural responses. ${ }^{7}$ Mak \& Cheung's Affiliate Stigma Scale was designed specifically to measure stigma experienced by family members of individuals with intellectual disabilities. ${ }^{7}$ Although the authors presented the scale as a unidimensional one, a recent study in Taiwan by Chang et al using Rasch analysis found three separate domains of the scale, tapping affect, cognitions and behaviours. ${ }^{13}$ The scale was developed for research in Hong Kong and China and subsequently translated into English. Critical examination of the scale's items indicates that it is unsuitable for a Western context and has limited applicability with people of different ethnicities. Some items were specific to Chinese culture and many others worded in a way that presumes having a child with IDD is of necessity a negative experience, making the scale unacceptable to parents in settings where such negative assumptions may be viewed very critically.

It remains unclear whether family members actually perceive stigma, their responses to it, whether there is a clear relationship between perception of stigma and its internalisation, or conversely, what factors determine whether they view themselves as stigmatised by others but reject this and assert their value and rights. Poor measurement of these constructs has limited research by reducing the interpretability of findings. As such, this study set out to develop and evaluate a new scale measuring different aspects of family stigma, focusing on caregivers of people with IDD, and suitable for use with people of diverse ethnicities. We also sought to determine which carer and 'cared for person' characteristics and contextual variables, including subjective well-being, caregiver burden, positive meaning in caregiving, self-esteem and social support, predict levels of family stigma. The term 'family stigma' is used 
throughout to collectively describe perceived family stigma and affiliate stigma.

\section{Method}

\section{Development phase and item generation}

Based on a search of the literature on the different aspects of family stigma outlined above, the Affiliate Stigma Scale, ${ }^{7}$ and ten other scales relating to stigma and caregiving, a pool of 56 items was constructed. These items addressed perceived family stigma, affiliate stigma and positive aspects of caregiving. To assess face and content validity, six senior psychiatrists and clinical psychologists who were experts working in IDD services, identified through the authors' professional networks, rated the clarity, relevance and wording of these items. Additionally, through email correspondence with the facilitators of a support group for carers of people with IDD, two focus groups with 18 carers of diverse ethnicities provided feedback on the item wording and format of the instrument. Their feedback was organised into themes that guided revision of the questionnaire. The revised version was piloted with ten carers before the final version, consisting of 28 items, was arrived at.

The questionnaire used the term 'learning disability', both as this is the most commonly used term in the UK to denote intellectual disability and as a primary focus for questions in the absence of a commonly used term such as IDD that encompasses intellectual disability and autism spectrum disorders. Responses were made using a five-point Likert scale ranging from strongly disagree (1) to strongly agree (5). A total stigma score was calculated by summing all responses. Scores range from 28 to 140, with a higher score indicating a higher level of stigma.

\section{Participants}

All participants were given an information sheet and provided written informed consent. The 28-item version of the measure was completed by 407 family carers of people with autism and intellectual disabilities residing in the UK via an internet survey. A total of $91.6 \%$ identified themselves as primary caregivers. Of the sample, $68.8 \%$ had another child without and $21.5 \%$ another child with IDD. Key information about the person they cared for is provided in Table 1.

\section{Procedure}

Family carers in the main study were recruited through advertisements. 462 UK-based organisations working with carers of people with IDD were approached. No response was received from 334

$\begin{array}{lrr}\text { Table } 1 \text { Information related to family member with intellectual } & \\ \text { disabilities } & n & \% \\ \text { Characteristics } & & \\ \text { Gender } & 278 & 68.3 \\ \quad \text { Male } & 129 & 31.7 \\ \quad \text { Female } & & \\ \text { Additional diagnoses } & 215 & 52.8 \\ \text { Autism spectrum disorder } & 74 & 18.2 \\ \text { Down syndrome } & 183 & 45.0 \\ \text { Other (includes fragile-X syndrome, cerebral palsy and } & & \\ \quad \text { those with an unknown additional diagnosis } & & \\ \text { Additional disabilities } & 74 & 18.2 \\ \text { Mobility } & 80 & 19.7 \\ \text { Epilepsy/seizure disorder } & 59 & 14.5 \\ \text { Vision impairment } & 38 & 9.3 \\ \text { Hearing impairment } & 119 & 29.2 \\ \text { Other } & \end{array}$

of these and 25 organisations declined. The remaining 103 disseminated information about the study via their social media sites and/or newsletters. In response, 407 family carers completed the survey online. To assess test-retest reliability, 55 participants completed the measure a second time approximately 6 weeks after initial completion. Ethical approval was granted by the authors' research ethics committee.

\section{Measures}

Subjective well-being was assessed using the Personal Wellbeing Index. ${ }^{14}$ This has eight items measuring satisfaction in the following life domains: standard of living, personal health, achieving in life, personal relationships, personal safety, community-connectedness, future security and religion, using a scale ranging from 0 , completely dissatisfied to 10 , completely satisfied. A ninth item 'leisure', added by Werner \& Shulman, was used in this study. ${ }^{10}$ Caregiving burden was assessed with a single item taken from Werner \& Shulman: 'to what degree do you feel burdened when you are with your child with a disability?', rated 1, never to 5, almost always. ${ }^{10}$ Self-esteem was measured using Rosenberg's tenitem Self-Esteem Scale, which is scored 0, strongly agree and 3, strongly disagree. ${ }^{15}$ The Multidimensional Scale of Perceived Social Support ${ }^{16}$ was used to assess perceptions of social support available from family, friends and a significant other, with higher scores indicating higher perceived social support.

In addition, participants indicated the presence of comorbid physical disabilities and provided a brief description of them in order to determine their visibility. Finally, challenging behaviour displayed by the cared for person was assessed using Part I and the first three items from Part II of the Challenging Behaviour Interview. ${ }^{17}$ This assessed whether the cared for person had displayed self-injury, physical or verbal aggression, disruption of the environment and/or inappropriate vocalisations within the last month - higher scores indicating increasingly challenging behaviour. Only the first three items from Part II measuring frequency, intensity and duration of each behaviour were used as the remaining items were not relevant to this study's focus.

\section{Results}

\section{Sociodemographic characteristics of participants}

Of the 407 participants, $91.6 \%$ were White, $7.8 \%$ Asian and the remainder of other ethnic backgrounds. Regarding age, 5.2\% were below 30 years of age, $38.6 \%$ between 45 and 54, 28.7\% between 31 and $44,18.2 \%$ between 55 and 64, and 9.3\% were 65 or older. The sample consisted primarily of mothers, who made up $79.4 \%$ of the sample, whereas the remaining were fathers (7.1\%), siblings $(8.6 \%)$ or other family members. Most carers were educated to age $18(53.1 \%)$ and $44.2 \%$ were university graduates. A total of $41.8 \%$ were in employment, $41.3 \%$ not in work, and the remainder were students or otherwise occupied.

\section{Factor analysis}

In a principal components analysis with oblique rotation (direct Oblimin), five factors had eigenvalues above Kaiser's criterion of 1 and in combination explained $60.5 \%$ of the variance. The KaiserMeyer-Olkin (KMO) value of 0.898 and Bartlett's test of sphericity $(\chi C ̧ \quad(231)=4645.603, P<0.0001)$, indicated excellent sampling adequacy and sufficiently large correlations between items for this analysis. Items with factor loadings greater than 0.5 and not cross loading on any other factor by more than 0.20 were retained, resulting in 26 items in the final scale (see Appendix Table 1). The first factor, which accounted for $27.7 \%$ of the total variance, represented 
perceived family stigma. The second factor explained $13.1 \%$ of the total variance and contained items about the affective aspects of affiliate stigma. The third factor related to the cognitive aspects of affiliate stigma and accounted for $6.1 \%$ of the total variance. The fourth factor accounted for only $4.4 \%$ of the variance and represented the behavioural aspects of affiliate stigma. As such, these three factors were labelled affective, cognitive and behavioural affiliate stigma. The final factor explained $9.3 \%$ of the variance and represented positive aspects of caregiving.

Notably, $66.1 \%$ of the participants perceived that the family would be excluded from social events (item 8 ) and $52.3 \%$ had been excluded (item 14) (see Appendix Table 1). Moreover, almost $79.1 \%$ were aware of the way other people looked at them when they were in public with the individual with IDD (item 15). Notably, there was unanimous disagreement with some of the items, for example items 18 and 20, suggesting that only a small minority of carers are heavily affected in terms of behavioural affiliate stigma. On the positive side, $60 \%$ felt that caring for their relative had given them a more positive outlook on life (item 21).

Perceived family stigma and each aspect of affiliate stigma were calculated using responses that were endorsed as either 'agree' or 'strongly agree'. Perceived family stigma was experienced by $59.3 \%$ of the respondents. Of the $34.5 \%$ who reported experiencing affiliate stigma, $11.4 \%$ endorsed items relating to the affective dimension, $65.9 \%$ those related to cognitive affiliate stigma and $5.7 \%$ items pertaining to the behavioural dimension.

\section{Test-retest reliability}

The average measure intraclass correlation (ICC) was 0.60 (95\% CI $0.34-0.76), F(62,62)=2.515, P<0.001$, indicating moderate reliability. The three affiliate stigma subscales, with ICCs of 0.68 for the affective dimension (95\% CI 0.47-0.81), 0.77 for the cognitive dimension (95\% CI 0.62-0.86) and 0.68 for the behavioural dimension (95\% CI 0.47-0.81) measured relatively stable dimensions over the 6-week retest period, as did the positive aspects of caregiving subscale (ICC $=0.78,95 \%$ CI $0.63-0.87$ ). However, the perceived family stigma subscale measured an unstable construct (ICC = 0.45, 95\% CI 0.09-0.67).

\section{Internal consistency and correlations}

Cronbach's alpha for the full 26-item scale was 0.84 , and $0.77-0.91$ for individual subscales, indicating good internal consistency for all parts of the scale (Table 2).

Correlations between the five factors were computed using Bonferroni adjusted alpha levels of 0.01 (Table 3 ). The four family stigma factors were intercorrelated in the 0.19-0.58 range, indicating that they tapped into related yet distinct aspects of stigma. Perceived family stigma was positive correlated with all three dimensions of affiliate stigma. The positive aspects of the caregiving subscale were negatively correlated with the affective and behavioural dimensions of affiliate stigma.

$\begin{array}{lcrr}\text { Table } 2 & \text { Reliability for subscales: Cronbach's alphas and descriptives } \\ \text { Subscale } & \text { Cronbach's } \alpha & \text { Mean } & \text { s.d. } \\ \text { Perceived family stigma } & 0.91 & 27.32 & 7.55 \\ \text { Affective affiliate stigma } & 0.82 & 6.32 & 3.34 \\ \text { Cognitive affiliate stigma } & 0.85 & 13.98 & 4.15 \\ \text { Behavioural affiliate stigma } & 0.77 & 5.81 & 2.73 \\ \text { Positive aspects of caregiving } & 0.78 & 19.83 & 5.20 \\ \text { Total scale } & 0.84 & 73.32 & 13.43\end{array}$

\section{Sociodemographic characteristics and affiliate stigma}

Independent $t$-tests, one-way ANOVAs, Pearson's correlations and regression analyses were computed to determine the associations between family stigma and caregiver and the cared for person's characteristics, with alpha levels Bonferroni adjusted. Subsequently, regression analyses were computed with the characteristics showing significant associations with the different dimensions of affiliate stigma to determine which of these were independently predictive (see Appendix Table 2). Two predictors, challenging behaviours and ethnicity, explained $5 \%$ of the variance in affective affiliate stigma. The four predictors that explained $10 \%$ of the variance in cognitive affiliate stigma were challenging behaviours, the carer's relationship to the individual with IDD, caregiver age and number of physical disabilities. The only predictor of behavioural affiliate stigma was challenging behaviour, explaining $50 \%$ of the variance. Challenging behaviour was also the only predictor for total affiliate stigma, accounting for $7 \%$ of the variance.

\section{Psychological and contextual variables and affiliate stigma}

Multiple regression analyses were conducted to assess the relationships between caregiving burden, subjective well-being, carer selfesteem, perceived social support and the different family stigma dimensions, with Sidak-Bonferroni adjusted alpha levels of 0.01 (see Appendix Table 3). Burden was the only significant predictor of affective affiliate stigma, with $16 \%$ of the variance explained by the model. Cognitive affiliate stigma was associated with positive aspects of caregiving, subjective well-being and burden, with the model accounting for $17.7 \%$ of the variance. Burden and subjective well-being explained $14.9 \%$ of the variance in behavioural affiliate stigma. Total affiliate stigma was associated with burden and subjective well-being, which accounted for $22.2 \%$ of the variance.

\section{Relative importance of sociodemographic, psychological and contextual variables}

In order to examine the relative importance of the caregiver/cared for characteristics and contextual variables, four separate multivariate linear regressions were computed with affective affiliate stigma, cognitive affiliate stigma, behavioural affiliate stigma and overall affiliate stigma as outcome variables. Post hoc corrections were made using the Sidak-Bonferroni correction and regressions were interpreted using adjusted alpha levels of 0.005 (Table 4).

For affective affiliate stigma, after correction, perceived family stigma, ethnicity and burden were predictive, explaining $3 \%$ of the variance. For cognitive affiliate stigma, after correction, perceived family stigma, caregivers' age and subjective well-being were predictive, explaining $31 \%$ of the variance. For behavioural affiliate stigma, perceived family stigma and burden were predictive after correction, explaining $7 \%$ of the variance. For total affiliate stigma, perceived family stigma, burden and subjective well-being were predictive.

\section{Discussion}

\section{Main findings}

The main aim of this study was to develop and validate a new measure of family stigma as experienced by family caregivers of people with autism and intellectual disabilities. Factor analysis of the FAMSI identified a 26-item, self-report measure that assesses perceived family stigma, its application to self and internalisation (affiliate stigma), and positive aspects of caregiving across five factors. Inclusion of items pertaining to positive aspects of 
Table 3 Correlations between Family Stigma Instrument subscales

\begin{tabular}{|c|c|c|c|c|}
\hline Subscales & Perceived family stigma & Affective affiliate stigma & Cognitive affiliate stigma & Behavioural affiliate stigma \\
\hline Perceived family stigma & - & & & \\
\hline Affective affiliate stigma & $0.17 * *$ & - & & \\
\hline Cognitive affiliate stigma & $0.55^{\star *}$ & $0.27 * *$ & - & \\
\hline Behavioural affiliate stigma & $0.21 * *$ & $0.58^{* *}$ & $0.32^{* *}$ & - \\
\hline Positive aspects of caregiving & -0.05 & $-0.14^{* *}$ & -0.04 & -0.20 ** \\
\hline
\end{tabular}

caregiving was deemed important because existing stigma scales neglect positive dimensions of the caregiving experience. As noted above, more than half of the family carers felt that caring for an individual with IDD had given them a more positive outlook on life.

The findings indicate that there may be two stages involved in the experience of stigma among family members of individuals with IDD. Initially, family carers may become aware of others' negative evaluations of the stigmatised individual and their family members, captured by the FAMSI's perceived family stigma subscale. Subsequently, they may experience this first hand (cognitive affiliate stigma), experience negative emotions associated with their caregiving role (affective affiliate stigma) and engage in behaviours concomitant with behavioural affiliate stigma, such as actively avoiding social interactions and being seen as related to the person with IDD. Almost $60 \%$ of family carers in this study felt that family members of people with IDD are at times stigmatised. A third appeared personally affected by family stigma, mostly in the form of the cognitive dimension, i.e. by perceiving themselves to be viewed or treated as less worthy by others. Around $11 \%$ reported negative emotions, such as discomfort, associated with having a family member with IDD and 6\% reported behavioural responses of avoidance and withdrawal.

\section{Interpretation of our findings}

Accordingly, perceived family stigma may prompt different processes that may involve indifference, active resistance or in turn negative self-evaluations and social comparisons, ${ }^{18}$ the latter initiating self-stigmatisation on the part of caregivers. The differential impact of stigma on family carers could be because of a number of reasons: carers who have had positive experiences of caregiving and who value their relationship with the individual with IDD may recognise others' negative responses but actively resist these or be less vulnerable to them as a result of perceiving their caring role and their loved one in positive terms. Research in the mental health field suggests that self-stigmatisation involves a sense of threat to one's sense of worth, regard and confidence. ${ }^{19}$ Therefore, a family carer who sees the individual with IDD or their relationship with them as undermining their fundamental worth may be more sensitive to others' negative reactions and more likely to internalise stigma.

Looking at factors that seem to influence these processes, the proportion of variance explained by sociodemographic and contextual variables in this study notably fluctuated for each aspect of affiliate stigma. Although the variables explained up to $31 \%$ of the variance for cognitive affiliate stigma in the final regression, they only accounted for $3 \%$ of the variance in affective affiliate stigma, $7 \%$ in behavioural affiliate stigma and $21 \%$ in total affiliate stigma. Perceived family stigma and caregiving burden predicted all aspects of affiliate stigma and individually or collectively emerged as more important predictors of all dimensions of affiliate stigma than the other factors considered. Carers who perceived more stigma directed at the family and who saw themselves as burdened by their caring role, were more likely to experience affective, cognitive and behavioural affiliate stigma. Similar findings on the role of caregiving burden in family stigma were reported by Mak

\begin{tabular}{|c|c|c|c|c|c|c|c|c|c|c|c|c|}
\hline \multirow[t]{2}{*}{ Variable } & \multicolumn{3}{|c|}{ Affective affiliate stigma } & \multicolumn{3}{|c|}{ Cognitive affiliate stigma } & \multicolumn{3}{|c|}{$\begin{array}{c}\text { Behavioural affiliate } \\
\text { stigma }\end{array}$} & \multicolumn{3}{|c|}{ Affiliate stigma } \\
\hline & $B$ & s.e. & $\beta$ & $B$ & s.e. & $\beta$ & $B$ & s.e. & $\beta$ & $B$ & s.e. & $\beta$ \\
\hline \multicolumn{13}{|l|}{ Step 1} \\
\hline Constant & 1.02 & 0.16 & & 1.45 & 0.12 & & 0.80 & 0.13 & & 1.09 & 0.11 & \\
\hline Perceived family stigma & 0.16 & 0.04 & $0.18^{* *}, \dagger$ & 0.61 & 0.05 & $0.55^{\star *}, \dagger$ & 0.19 & 0.04 & $0.26^{* *}, \dagger$ & 0.32 & 0.03 & $0.46^{* *}, \dagger$ \\
\hline \multicolumn{13}{|l|}{ Step 2} \\
\hline Constant & 2.07 & 0.49 & & 3.34 & 0.52 & & 2.30 & 0.41 & & 2.54 & 0.34 & \\
\hline Perceived family stigma & 0.15 & 0.04 & $0.16^{* *}, \dagger$ & 0.52 & 0.04 & $0.47 * *, \dagger$ & 0.14 & 0.04 & $0.19 * *, \dagger$ & 0.27 & 0.03 & $0.39 * *, \dagger$ \\
\hline Challenging behaviours & 0.01 & 0.01 & 0.07 & 0.01 & 0.01 & 0.04 & 0.02 & 0.01 & $0.10^{*}$ & 0.01 & 0.01 & $0.09 *$ \\
\hline Relationship to individual $^{a}$ & 0.07 & 0.10 & 0.03 & -0.10 & 0.10 & -0.04 & 0.07 & 0.80 & 0.04 & 0.01 & 0.07 & 0.01 \\
\hline Caregiver age ${ }^{\mathrm{b}}$ & 0.02 & 0.04 & 0.03 & -0.19 & 0.04 & $-0.19 * *, \dagger$ & $<0.00$ & 0.03 & $<0.00$ & -0.05 & 0.03 & $-0.08^{*}$ \\
\hline Number of physical disabilities ${ }^{c}$ & -0.14 & 0.05 & $-0.13^{* *}$ & 0.06 & 0.05 & 0.05 & -0.10 & 0.04 & $-0.18^{* *}$ & -0.06 & 0.03 & -0.07 \\
\hline Ethnicity ${ }^{d}$ & 0.41 & 0.14 & $0.13^{* *}, \dagger$ & -0.24 & 0.15 & -0.06 & 0.15 & 0.12 & 0.06 & 0.11 & 0.10 & 0.05 \\
\hline Burden & -0.25 & 0.04 & $-0.35^{* *}, \dagger$ & -0.10 & 0.04 & $-0.11 * *$ & -0.10 & 0.00 & $-0.17 * *, \dagger$ & -0.15 & 0.03 & $-0.27^{* *}, \dagger$ \\
\hline Positive meaning in caregiving & -0.06 & 0.05 & -0.07 & 0.11 & 0.05 & $0.09 *$ & -0.64 & 0.40 & -0.08 & -0.01 & 0.03 & -0.02 \\
\hline Subjective well-being & -0.01 & 0.03 & -0.03 & -0.10 & 0.03 & $-0.22^{* *}, \dagger$ & -0.06 & 0.02 & $-0.17^{* *}$ & -0.05 & 0.02 & $-0.18^{* *}, \dagger$ \\
\hline Self-esteem & -0.22 & 0.14 & -0.07 & -0.09 & 0.15 & -0.02 & 0.26 & 0.12 & $-0.11^{\star}$ & -0.19 & 0.10 & -0.08 \\
\hline Social support & 0.07 & 0.03 & $0.12^{*}$ & $<0.00$ & 0.04 & $<0.00$ & 0.02 & 0.03 & 0.03 & 0.03 & 0.02 & 0.06 \\
\hline$R^{2}$ & & & 0.03 & & & 0.31 & & & 0.07 & & & 0.21 \\
\hline$\Delta R^{2}$ & & & 0.19 & & & 0.12 & & & 0.14 & & & 0.17 \\
\hline$F$ for $\Delta R^{2}$ & & & $9.31 * *, \dagger$ & & & $8.46^{* *}, \dagger$ & & & $6.86^{* *}, \dagger$ & & & $10.5^{* *}, \dagger$ \\
\hline
\end{tabular}


\& Cheung ${ }^{7}$ and Werner \& Shulman. ${ }^{11}$ Caregiving burden was most strongly associated with the affective dimension, suggesting that it plays an important part in feelings of shame, despair and embarrassment on the part of family carers. Facing the embarrassment caused by one's relative displaying characteristics and behaviours that challenge social and cultural norms and may attract unwanted attention may result in emotional and psychological distress in carers. ${ }^{20}$

Another important finding is that higher subjective well-being on the part of the carer was associated with reduced cognitive and behavioural stigma. This suggests that perceived family stigma and subjective burden may act as risk factors for affiliate stigma whereas subjective well-being may have a protective function. Accordingly, interventions aimed at tackling affiliate stigma need to pay careful attention to caregiving burden experienced by family members and, most crucially, need to involve challenging perceived family stigma. At present we have little understanding how this can be achieved but empowering family carers to actively resist negative responses they witness directed at family members of people with IDD merits consideration.

Contrary to evidence that older caregivers as more likely to internalise stigma that affects their quality of life, admittedly generated in a Chinese context, ${ }^{6,21}$ the present results suggest that younger family members of individuals with IDD experience higher levels of cognitive affiliate stigma. As a result of a changing societal context and the increasing emphasis on the rights of the individual, including those with disabilities, younger relatives may be more alert to stigma and also less willing to tolerate it. Older parents may be less sensitive to hostile responses, or conversely, may have developed and adopted strategies that help them cope with others' negative attitudes and discrimination. ${ }^{22}$

With regards to ethnicity, family carers from ethnic minority backgrounds reported more affective affiliate stigma even when controlling for perceived family stigma. This may have two immediate explanations: first, it has been suggested that stigma associated with IDD is higher among Black and Asian communities in the $\mathrm{UK}^{23}$ Second, within Asian communities, where every member of the family is seen to play a part in upholding the reputation of the family and determine its social standing, ${ }^{24}$ family members, and mothers in particular, may be at greater risk of experiencing discomfort and distress about having a family member with IDD.

As to factors connected to the characteristics of the person cared for, family carers who reported higher levels of challenging behaviour displayed by their family member were more vulnerable to all aspects of affiliate stigma. This seems unsurprising given that challenging behaviours may attract negative evaluations from others and an awareness of these may in turn induce negative emotions, thoughts and behavioural responses in the family member. However, the contribution of challenging behaviours disappeared for all aspects of affiliate stigma when perceived family stigma was controlled for in the final regression analyses. Indeed, an initial awareness of stigma may be largely dependent on the nature and extent of challenging behaviours displayed by the individual when the family carer is in public with them. Repeated negative interactions may gradually become associated with increased perceived family stigma and threat to one's confidence and sense of worth. ${ }^{25}$

\section{Limitations}

Several limitations require mention: it is possible that face-to-face administration of the measures may have been preferable to online administration given the sensitive nature of the experience of caregiving and stigma. Electronic administration may also introduce self-selection and drop-out biases associated with internet research. Older carers and those from ethnic minority backgrounds are perhaps less likely to use the internet and English may not be their first language.

The original Challenging Behaviour Interview was adapted for the study, hence its psychometric properties may differ from the original. ${ }^{26}$ Some individuals with IDD had more than one primary diagnosis, were awaiting assessment or caregivers were unsure of confirmed additional diagnoses. Moreover, information about additional diagnoses and challenging behaviour were based on carers' subjective reports alone and were not confirmed by a clinician or additional informant.

The test-retest reliability of the perceived stigma subscale was fair. Given the central role of perceived family stigma that emerged in this study, further work is needed to consider how to measure this construct in a sound manner. For the present we advise relying more on responses on the cognitive affiliate stigma subscale, which proved more stable over time, which is perhaps not surprising as they tap awareness of stigma directed at oneself and not at other family members of people with IDD.

A further potential limitation relates to the exploratory analysis conducted in this paper. The analyses did not investigate how the scale behaves across groups and other covariates before conducting $t$-tests and other analyses. Exploring measurement invariance and differential item functioning will be an extension of this research in future studies.

\section{Implications}

In summary, attention to family carers' perceptions and experiences related to stigma may hold important clues to their sense of wellbeing and likelihood of experiencing caregiving in positive terms or conversely as burdensome. The FAMSI offers a brief tool that when used alongside clinical interview, and possibly the brief measures of subjective well-being and burden employed in this study, may sensitise clinicians and researchers to family carers' perspectives of their position in their family, community and society and to the potential harmful effects of affiliate stigma.

Natasha Mitter, Clinical Psychologist, Division of Psychology and Language Sciences, University College London, UK; Afia Ali, Senior Clinical Lecturer, Division of Psychiatry, University College London, UK; Katrina Scior, Senior Lecturer, Division of Psychology and Language Sciences, University College London, UK

Correspondence: Katrina Scior, Division of Psychology and Language Sciences, University College London, London WC1E 6BT, UK. Email: k.scior@ucl.ac.uk First received 30 Jan 2018, final revision 4 Jun 2018, accepted 8 Jun 2018

\section{References}

1 European Union Monitoring and Advocacy Programme. Access to Education and Employment for People with Intellectual Disabilities. European Union Monitoring and Advocacy Programme, 2005. (https://www.opensocietyfoundations.org/sites/default/files/hungary_0.pdf).

2 Goffman E. Stigma: Notes on the Management of Spoiled Identity. Simon \& Schuster, 1963

3 Bos AER, Pryor JB, Reeder GD, Stutterheim SE. Stigma: advances in theory and research. Basic Appl Soc Psychol 2013; 35: 1-9.

4 Yang LH, Kleinman A, Link BG, Phelan JC, Lee S, Good B. Culture and stigma: adding moral experience to stigma theory. Soc Sci Med 2007; 64: 1524-35.

5 Mehta S, Farina A. Associative stigma: perceptions of the difficulties of collegeaged children of stigmatized fathers. J Soc Clin Psychol 1988; 7: 192-202.

6 Chiu MYL, Yang X, Wong FHT, Li JH. Caregiving of children with intellectual disabilities in China - an examination of affiliate stigma and the cultural thesis. $J$ Intellect Disabil Res 2013; 57: 1117-29.

7 Mak WWS, Cheung RYM. Affiliate stigma among caregivers of people with intellectual disability or mental illness. J Appl Res Intellect Disabil 2008; 21: 532-45.

8 Mak WWS, Cheung RYM. Self-Stigma among concealable minorities in Hong Kong: conceptualization and unified measurement. Am J Orthopsychiatry 2010; 80: 267-81. 
9 Mak WWS, Kwok YTY. Internalization of stigma for parents of children with autism spectrum disorder in Hong Kong. Soc Sci Med 2010; 70: 2045-51.

10 Werner S, Shulman C. Subjective well-being among family caregivers of individuals with developmental disabilities: the role of affiliate stigma and psychosocial moderating variables. Res Dev Disabil 2013; 34: 4103-14.

11 Werner S, Shulman C. Does type of disability make a difference in affiliate stigma among family caregivers of individuals with autism, intellectual disability or physical disability? J Intellect Disabil Res 2015; 59: 272-83.

12 Maio GR, Haddock G. The Psychology of Attitudes and Attitude Change (2nd edn). Sage, 2015.

13 Chang CC, Su JA, Tsai CS, Yen CF, Liu JH, Lin CY. Rasch analysis suggested three unidimensional domains for affiliate stigma scale: additional psychometric evaluation. J Clin Epidemiol 2015; 68: 674-83.

14 Personal Wellbeing Index - Adult (PWI-A). 5th ed., 2013 (http://www.acqol. com.au/instruments).

15 Rosenberg M. Society and the Adolescent Self-Image. Princeton University Press, 1965.

16 Zimet GD, Dahlem NW, Zimet SG, Farley GK. The multidimensional scale of perceived social support. J Personal Assess 1988; 52: 30-41.

17 Oliver C, McClintock K, Hall S, Smith M, Dagnan D, Stenfert-Kroese B. Assessing the severity of challenging behaviour: psychometric properties of the Challenging Behaviour Interview. J Appl Res Intellect Disabil 2003; 16: 53-61.

18 Ali A, Hassiotis A, Strydom A, King M. Self-stigma in people with intellectual disabilities and courtesy stigma in family carers: a systematic review. Res Dev Disabil 2012; 33: 2122-40.
19 Vogel D, Wade N. Stigma and help-seeking. Psychologist 2009; 22: 20-23. (https://thepsychologist.bps.org.uk/volume-22/edition-1/stigma-and-helpseeking).

20 Green SE. 'What do you mean "what's wrong with her?"': stigma and the lives of families of children with disabilities. Soc Sci Med 2003; 57: 1361-74.

21 Chou YC, Pu CY, Lee YC, Lin LC, Kröger T. Effect of perceived stigmatisation on the quality of life among ageing female family carers: a comparison of carers of adults with intellectual disability and carers of adults with mental illness. J Intellect Disabil Res 2009; 53: 654-64.

22 Sarkar A. Stigma Experienced by Parents of Adults with Intellectual Disabilities (MSc thesis). Department of Community Health \& Epidemiology, Queen's University, Kingston, Canada, 2010 (https://qspace.library. queensu.ca).

23 Scior K, Potts HW, Furnham AF. Awareness of schizophrenia and intellectual disability and stigma across ethnic groups in the UK. Psychiatry Res 2013; 208: 125-130.

24 Leake D, Black R. Essential Tools: Cultural and Linguistic Diversity: Implications for Transition Personnel. University of Minnesota, Institute on Community Integration, National Center on Secondary Education and Transition, 2005.

25 Cantwell J, Muldoon O, Gallagher S. The influence of self-esteem and social support on the relationship between stigma and depressive symptomology in parents caring for children with intellectual disabilities. J Intellect Disabil Res 2015; 59: 948-57.

26 Streiner DL, Norman GR, Cairney J. Health Measurement Scales: A Practical Guide to Their Development and Use. Oxford University Press, 2015.

\section{Appendix}

\begin{tabular}{|c|c|c|c|c|c|c|}
\hline Item & $\begin{array}{l}\text { Factor } \\
\text { Loading }\end{array}$ & $\begin{array}{l}\text { Strongly } \\
\text { disagree } n \\
\text { (\%) }\end{array}$ & $\begin{array}{c}\text { Somewhat } \\
\text { disagree } n(\%)\end{array}$ & $\begin{array}{c}\text { Neither disagree } \\
\text { nor agree } n(\%)\end{array}$ & $\begin{array}{l}\text { Somewhat } \\
\text { agree } n(\%)\end{array}$ & $\begin{array}{l}\text { Strongly } \\
\text { agree } n(\%)\end{array}$ \\
\hline \multicolumn{7}{|l|}{ Factor 1: Perceived family stigma $(\alpha=0.91)$} \\
\hline $\begin{array}{l}\text { Some people might feel embarrassed about } \\
\text { associating with the family of someone with IDD. }\end{array}$ & 0.791 & $39(9.6)$ & $56(13.8)$ & $50(12.3)$ & $204(50.1)$ & $58(14.3)$ \\
\hline $\begin{array}{l}\text { Some people might feel uncomfortable about going } \\
\text { to the house of the family of someone with IDD. }\end{array}$ & 0.775 & $34(8.4)$ & $42(10.3)$ & $66(16.2)$ & $210(51.6)$ & 55 (13.5) \\
\hline $\begin{array}{l}\text { Some people might treat the family of someone } \\
\text { with IDD more negatively. }\end{array}$ & 0.900 & $33(8.1)$ & $42(10.3)$ & $64(15.7)$ & $190(46.7)$ & 77 (18.9) \\
\hline $\begin{array}{l}\text { Some people might think that the family has done } \\
\text { something wrong because of the person with IDD. }\end{array}$ & 0.658 & $87(21.4)$ & 85 (20.9) & $99(24.3)$ & $101(24.8)$ & $33(8.1)$ \\
\hline $\begin{array}{l}\text { Some people might behave negatively towards the } \\
\text { family of someone with IDD when they are with } \\
\text { the person with IDD in public. }\end{array}$ & 0.821 & $52(12.8)$ & $62(15.2)$ & 79 (19.4) & $162(39.8)$ & $51(12.5)$ \\
\hline $\begin{array}{l}\text { Some people might avoid making friends with the } \\
\text { family of someone with IDD. }\end{array}$ & 0.805 & $37(9.10)$ & $35(8.6)$ & $60(14.7)$ & $184(45.2)$ & 89 (21.9) \\
\hline $\begin{array}{l}\text { Some people might not want to hear about any of } \\
\text { the problems of the family of someone with IDD. }\end{array}$ & 0.746 & $32(7.9)$ & $56(13.8)$ & 70 (17.2) & $164(40.3)$ & 85 (20.9) \\
\hline $\begin{array}{l}\text { Some people might not invite the family of } \\
\text { someone with IDD to social events. }\end{array}$ & 0.621 & $42(10.3)$ & $49(12.0)$ & $47(11.5)$ & $158(38.8)$ & $111(27.3)$ \\
\hline \multicolumn{7}{|l|}{ Factor 2: Affective affiliate stigma } \\
\hline $\begin{array}{l}\text { I feel embarrassed about my family member with } \\
\text { IDD. }\end{array}$ & -0.793 & $281(69.0)$ & 45 (11.1) & $28(6.9)$ & 48 (11.8) & $5(1.2)$ \\
\hline $\begin{array}{l}\text { I feel distressed about being associated with my } \\
\text { family member with IDD. }\end{array}$ & -0.766 & $329(80.8)$ & $35(8.6)$ & $23(5.7)$ & $12(2.9)$ & $4(1.0)$ \\
\hline $\begin{array}{l}\text { I feel guilty about having my family member with } \\
\text { IDD in the family. }\end{array}$ & -0.796 & 327 (80.3) & $33(8.1)$ & $16(3.9)$ & $26(6.4)$ & $4(1.0)$ \\
\hline $\begin{array}{l}\text { I feel uncomfortable when I have friends over } \\
\text { because of my family member with IDD. }\end{array}$ & -0.631 & $243(59.7)$ & 48 (11.8) & 27 (6.6) & $76(18.7)$ & $11(2.7)$ \\
\hline \multicolumn{7}{|l|}{ Factor 3: Cognitive affiliate stigma } \\
\hline $\begin{array}{l}\text { I am treated differently by some people when I am } \\
\text { with my family member with IDD. }\end{array}$ & -0.788 & $65(16.0)$ & $44(10.8)$ & $50(12.3)$ & $194(47.7)$ & $52(12.8)$ \\
\hline $\begin{array}{l}\text { I am excluded from activities when other people } \\
\text { find out about their IDD. }\end{array}$ & -0.745 & $78(19.2)$ & $53(13.0)$ & $62(15.2)$ & $162(39.8)$ & $51(12.5)$ \\
\hline
\end{tabular}




\begin{tabular}{|c|c|c|c|c|c|c|}
\hline Item & $\begin{array}{l}\text { Factor } \\
\text { Loading }\end{array}$ & $\begin{array}{l}\text { Strongly } \\
\text { disagree } n \\
\text { (\%) }\end{array}$ & $\begin{array}{c}\text { Somewhat } \\
\text { disagree } n(\%)\end{array}$ & $\begin{array}{c}\text { Neither disagree } \\
\text { nor agree } n(\%)\end{array}$ & $\begin{array}{l}\text { Somewhat } \\
\text { agree } n(\%)\end{array}$ & $\begin{array}{l}\text { Strongly } \\
\text { agree } n(\%)\end{array}$ \\
\hline $\begin{array}{l}\text { I am aware of how some people look at me when I } \\
\text { am out with my family member with IDD. }\end{array}$ & -0.752 & $30(7.4)$ & $20(4.9)$ & $32(7.9)$ & $184(45.2)$ & $138(33.9)$ \\
\hline $\begin{array}{l}\text { I am treated differently by some people because of } \\
\text { my family member with IDD. }\end{array}$ & -0.808 & $32(7.9)$ & $29(7.1)$ & $54(13.3)$ & $200(49.1)$ & $91(22.4)$ \\
\hline \multicolumn{7}{|l|}{ Factor 4: Behavioural affiliate stigma } \\
\hline $\begin{array}{l}\text { I avoid introducing my friends to my family member } \\
\text { with IDD. }\end{array}$ & 0.704 & $274(67.3)$ & $53(13.0)$ & $49(12.0)$ & $18(4.4)$ & $11(2.7)$ \\
\hline $\begin{array}{l}\text { I avoid telling people that I am related to my family } \\
\text { member with IDD. }\end{array}$ & 0.862 & $341(83.8)$ & $36(8.8)$ & $21(5.2)$ & $3(0.7)$ & $2(0.5)$ \\
\hline $\begin{array}{l}\text { I avoid making new friends because of my family } \\
\text { member with IDD. }\end{array}$ & 0.653 & $254(62.4)$ & $54(13.3)$ & $46(11.3)$ & $39(9.6)$ & $9(2.2)$ \\
\hline I avoid being seen with my family member with IDD. & 0.746 & $354(87.0)$ & $27(6.6)$ & $11(2.7)$ & $9(2.2)$ & $2(0.5)$ \\
\hline \multicolumn{7}{|l|}{ Factor 5: Positive aspects of caregiving } \\
\hline $\begin{array}{l}\text { Caring for my family member with IDD has enabled } \\
\text { me to develop a more positive attitude toward life. }\end{array}$ & 0.733 & $38(9.3)$ & $63(15.5)$ & $62(15.2)$ & $120(29.5)$ & $124(30.5)$ \\
\hline $\begin{array}{l}\text { Caring for my family member with IDD has made } \\
\text { me feel needed. }\end{array}$ & 0.579 & $27(6.6)$ & $25(6.1)$ & $116(28.5)$ & $118(29.0)$ & $120(29.5)$ \\
\hline $\begin{array}{l}\text { Caring for my family member with IDD has } \\
\text { strengthened my spirituality and faith. }\end{array}$ & 0.680 & $119(29.2)$ & $50(12.3)$ & $133(32.7)$ & $56(13.8)$ & $49(12.0)$ \\
\hline $\begin{array}{l}\text { Caring for my family member with IDD has allowed } \\
\text { me to form friendships with others in a similar } \\
\text { situation. }\end{array}$ & 0.603 & $29(7.1)$ & $43(10.6)$ & $54(13.3)$ & $145(35.6)$ & $136(33.4)$ \\
\hline $\begin{array}{l}\text { Caring for my family member with IDD has made } \\
\text { me feel that I make a positive contribution to } \\
\text { society. }\end{array}$ & 0.799 & $46(11.3)$ & $65(16.0)$ & $120(29.5)$ & $97(23.8)$ & $75(18.4)$ \\
\hline $\begin{array}{l}\text { Caring for my family member with IDD has } \\
\text { strengthened some of my relationships with } \\
\text { family/friends. }\end{array}$ & 0.705 & $68(16.7)$ & $99(24.3)$ & $100(24.6)$ & $92(22.6)$ & $47(11.5)$ \\
\hline
\end{tabular}

\begin{tabular}{|c|c|c|c|c|c|c|c|c|c|c|c|c|}
\hline \multirow[t]{2}{*}{ Characteristic } & \multicolumn{3}{|c|}{ Affective affiliate stigma } & \multicolumn{3}{|c|}{ Cognitive affiliate stigma } & \multicolumn{3}{|c|}{ Behavioural affiliate stigma } & \multicolumn{3}{|c|}{ Total affiliate stigma } \\
\hline & B & SE B & $\beta$ & B & SE B & $\beta$ & B & SE B & $\beta$ & B & SE B & $\beta$ \\
\hline Relationship to individual $^{a}$ & -0.03 & 0.10 & -0.01 & -0.35 & 0.12 & $-0.14^{* *}$ & -0.04 & 0.08 & -0.02 & -0.13 & 0.08 & -0.08 \\
\hline Caregiver age ${ }^{\mathrm{b}}$ & 0.03 & 0.04 & 0.05 & -0.15 & 0.05 & $-0.15^{\star \star}$ & 0.01 & 0.03 & 0.02 & -0.03 & 0.03 & -0.05 \\
\hline Ethnicity ${ }^{c}$ & 0.46 & 0.15 & $0.15^{\star *}$ & -0.25 & 0.18 & -0.07 & 0.15 & 0.12 & 0.06 & 0.12 & 0.11 & 0.05 \\
\hline Diagnoses $^{\mathrm{d}}$ & -0.04 & 0.04 & -0.05 & -0.01 & 0.05 & -0.01 & -0.02 & 0.04 & -0.03 & -0.03 & 0.03 & -0.04 \\
\hline No. of physical disabilities ${ }^{e}$ & -0.07 & 0.05 & -0.07 & 0.18 & 0.06 & $0.14 * *$ & -0.04 & 0.04 & -0.05 & 0.02 & 0.04 & 0.03 \\
\hline Challenging behaviour $^{f}$ & 0.03 & 0.01 & $0.15^{\star \star}$ & 0.04 & 0.01 & $0.17^{\star *}$ & 0.03 & 0.01 & $0.21^{\star \star}$ & 0.03 & 0.01 & $0.23^{* *}$ \\
\hline$R^{2}$ & & & 0.05 & & & 0.10 & & & 0.05 & & & 0.07 \\
\hline$F$ & & & $3.61^{* *}$ & & & $7.72^{\star \star}$ & & & $3.52^{\star \star}$ & & & $5.01^{* *}$ \\
\hline \multicolumn{13}{|c|}{$\begin{array}{l}\text { a. Relationship to individual: } 0=\text { mothers, } 1=\text { all others. } \\
\text { b. Caregiver age: } 1=<30,2=31-44,3=44-54,4=55-65,5=55-65,6=>65 \text {. } \\
\text { c. Ethnicity: } 0=\text { White, } 1=0 \text { other. } \\
\text { d. Additional diagnoses: } 1=1 D \text { only, } 2=1 D+A S D, 3=1 D+D S / O \text { ther, } 4=1 D+\geq 2 \text {. } \\
\text { e. Number of physical disabilities: } 0=\text { none, } 1=<2,2=\geq 3 \text {. }\end{array}$} \\
\hline
\end{tabular}

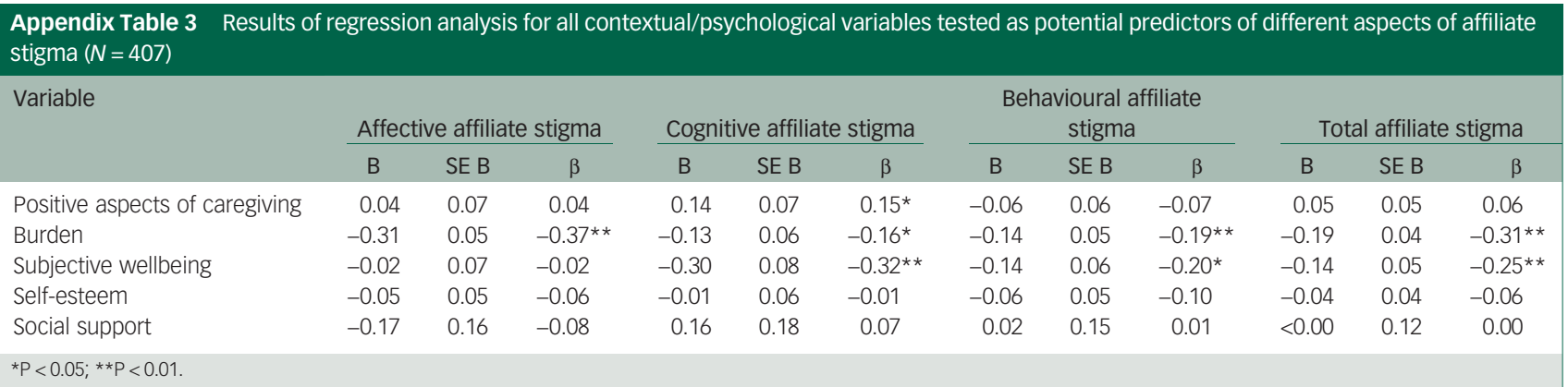

